\title{
A review of the fundamental factors and processes leading to the accumulation of aflatoxins in cereal crops
}

\author{
Kiran Bhardwaj ${ }^{1}$, Saowalak Adunphatcharaphon ${ }^{2}$, Kaushik Banerjee ${ }^{3}$, Christopher Elliott ${ }^{1}$, Awanwee \\ Petchkongkaew ${ }^{1,2}$ and Oluwatobi Kolawole ${ }^{1 *}$
}

${ }^{1}$ Institute for Global Food Security, School of Biological Science, Queen's University Belfast, 19 Chlorine Gardens Belfast BT9 5DL, Northern Ireland 2School of Food Science and Technology, Faculty of Science and Technology, Thammasat University, 99 Mhu 18, Phahonyothin road, KhongLuang, PathumThani 12120, Thailand

${ }^{3}$ National Reference Laboratory, ICAR-National Research Centre for Grapes, Pune 412307, India

*Corresponding author: oluwatobi.kolawole@qub.ac.uk

\begin{abstract}
Aflatoxins (AFs) contamination of cereals is considered one of the greatest food safety concerns worldwide. Occurrence of AFs in maize, wheat, rice and sorghum is highly prevalent with each commodity accounting for more than $10 \%$ of world's AF exposure. Their occurrence as food contaminants is also associated with huge economic losses. AFs are highly stable compounds that cannot be eliminated by regular processing of grains. Hence, prevention of AFs in food and feed is now considered more important than the subsequent interventions to mitigate the deleterious health effects of AFs in human and animals. However, the development of an effective preventive strategy hinges on a clear understanding of the underlying factors influencing AFs production. Therefore, the present review aims to highlight the most significant factors influencing AFs contamination of cereals at pre-and post-harvest stages. This is crucial for effective monitoring of critical control points and optimisation of preventive strategies in food and feed supply chains. Several intrinsic and extrinsic factors have been reported of which nutritional composition, environmental factors (temperature, water activity and relative humidity) and climate change have been identified as primary factors, while $\mathrm{pH}$ of the substrate, carbon dioxide $\left(\mathrm{CO}_{2}\right)$ levels in the gaseous environment, and agronomic and socioeconomic status are the main secondary factors promoting AFs biosynthesis in cereals. Additionally, an overview of global occurrence of AFs in cereals, with their health impacts and various preventive measures have also been highlighted.
\end{abstract}

Keywords: Aflatoxin contamination; Cereals; Intrinsic factors; Extrinsic factors; Climate change; Mitigation strategies

\section{Introduction}

Contamination of agricultural commodities by mycotoxins has been prevalent from time immemorial, but due to their increased occurrence due to a range of factors in various food commodities, especially cereals, they have been considered as one of the greatest food safety concerns worldwide. Cereal grains, key staples of the human diet, are highly susceptible to mycotoxin contamination [1-2]. Eskola et al. [3] reported that the world's food crop contamination with mycotoxins has now increased to $60-80 \%$, which was earlier estimated at $25 \%$ by the FAO. Several filamentous fungi produce mycotoxins as their secondary metabolites [4]. These metabolites are extracellular materials and do not play any specific role in their growth [5]. Species of Aspergillus, Penicillium and Fusarium are mainly responsible for mycotoxin production in cereal crops [6]; antibiotics and toxins produced by mushrooms and yeasts are excluded from this group [4-5]. Nearly 400 toxic

fungal metabolites have been identified and reported to be frequent contaminant of food and feed [6]. However, AFs, ochratoxins, deoxynivalenol or vomitoxin, zearalenone, patulin, fumonisins, citrinin, T-2 and HT-2 toxins, and Ergot alkaloids (EAs) are of the greatest importance with respect to food and feed safety [3]. Human and animals are exposed to mycotoxins via consumption of contaminated food and feed. Such exposures, whether acute or chronic, may exert toxic effects (known as mycotoxicosis) that maybe mild or severe, depending on exposure levels, time course, age, sex, and health status [7-10].

From all the above-mentioned metabolites, AFs are the most toxic and frequent contaminant of agricultural commodities, especially in areas with hot and humid climates [11]. Currently, more than 20 types of AFs analogues have been 
identified. However, aflatoxin B1 (AFB1), B2 (AFB2), G1 (AFG1) and G2 (AFG2) are the most prevalent in food and feed [18]. Their occurrence in maize, wheat, rice and sorghum is highly prevalent with each commodity accounting for more than $10 \%$ of world's AFs exposure [3]. Strains of A. flavus and A. parasiticus are known to be the major producers of AFs in cereals. Other less dominant species of Aspergillus including A. niger, A. nomius, A. pseudotamari, A. fumigates, A. ochraceoroseus and A. bombycids have also been reported to produce AFs [12-13]. Aflatoxicosis, a severe health condition, is a consequence of direct exposure to AFs via ingestion of contaminated grains. The toxicity of AFs can range from immune suppression to the induction of teratogenic, mutagenic, and carcinogenic activities $[9,14]$. Exposure of livestock animals to AFs-contaminated feed can lead to reduction in body weight due to reduced feed conversion or feed refusal, increased incidences of diseases, low quality of eggshell and carcass, impairment of reproductive health and contamination of dairy milk with aflatoxin M1 (AFM1) [9]. Consequently, the International Agency for Research on Cancer (IARC) has classified all four AFs and AFM1 as human carcinogens belonging to Group 1 and Group 2B, respectively [15]. Furthermore, most countries have established regulatory limits for either AFB1 or total aflatoxins (i.e., sum of AFB1, AFB2, AFG1, and AFG2) as well as AFM1 [9]. Their frequent occurrence in agricultural commodities not only jeopardises human health but also result in large economic losses arising from pre- and post-harvest losses of contaminated crops, increased cost of healthcare and testing facilities, investment in R\&D and the cost associated with regulatory framework to develop and implement effective risk assessment and management practices [16]. AFs contamination of cereals is a major problem in tropical and sub-tropical areas where the harsh and humid climate favour the growth of AFs-producing fungal species [14]. Fungal infection and its subsequent propagation may initiate at any time during pre-harvest (in-field), harvest and post-harvest (storage, transportation, and processing) of cereals [16]. Surveys conducted to evaluate the levels of AFs in cereal crops showed that maize is the most susceptible commodity to AFs, with rice being the least affected [4].

Mycotoxins, including AFs, are highly stable and difficult to be eliminated during regular processing of grains [7]. Hence, prevention of AFs in grains is now considered more important than the subsequent interventions to reduce health risks posed by these toxic metabolites. Several preventive measures including the development of resistant cultivars, implementation of Good Agricultural Practices (GAP), adoption of chemical and bio-control methods and adequate management of storage conditions have been proposed by several researchers to mitigate AFs contamination before and after harvest [14]. However, the development of an effective preventive strategy is highly dependent on accurate knowledge of the underlying factors influencing AFs production. In view of the above, the present review article has been written with the aim of highlighting the most significant factors responsible for AFs contamination of cereal crops at pre- and post-harvest levels. This is vital for effective monitoring of the critical control points and optimisation of preventive strategies in food and feed supply chains. Additionally, an overview of global occurrence of AFs in cereals along with their health impacts and preventive measures that could be applied at various stages of supply chain have been highlighted.

\section{Global occurrence of aflatoxins in cereal grains}

Cereals, edible grains of Gramineae family, are a rich source of essential macro and micronutrients. Due to their high nutritional value, they constitute a substantial portion of the human diet in developed as well as in developing countries and are cultivated widely throughout the globe [17]. Global cereal consumption and production rates are expected to rise by $1.2 \%$ annually until 2028 , with maize, wheat and rice the major contributors, and coarse cereals such as sorghum and barley as the minor contributors [18]. Despite the continuous efforts to prevent fungal infection and mycotoxin contamination, AFs are still widely prevalent in cereals harvested in different countries. A three-year mycotoxin survey revealed that majority of the studies on mycotoxin occurrence in commodities have been conducted in corn, wheat and rice, with AFB1 being the most prevalent mycotoxin often at levels exceeding regulatory limits [19]. Ismail et al. [20] summarised the data on global prevalence of AFs in different cereals (maize, rice, wheat, barley) and found that $33.54 \%$ samples were contaminated with AFs. A similar study evaluating data published on AFB1 contamination across the globe over a period of ten years i.e., $2008-2018$, highlighted that $44.8 \%$ wheat, $55.4 \%$ rice, $46.1 \%$ maize and $67.3 \%$ sorghum samples were found positive for AFB1 [21]. Results of the meta-analysis (1983-2017) carried out by Khaneghah et al. [9] also revealed that $30 \%$ of cereal-based food products were contaminated with AFs. An incidence rate of $55 \%$ was also recorded for total AFs in in cereals grown in Africa, America, Asia and Europe between 2006 and 2016 [9]. Overall, these studies indicate that cereal grains, especially corn, wheat and rice are frequently contaminated by AFs, with incidences and concentrations largely dependent on geographical location and agronomic factors. A summary of recent studies (2016-2021) on prevalence and concentrations of AFs in cereals is shown in Table 1. 
Table 1. Recent studies (2016 -2021) on occurrence of aflatoxin $\mathrm{B} 1\left(\mathrm{AFB}_{1}\right)$ and sum of aflatoxins $(\mathrm{AFs})$ in different types of cereals nd: Not detected;

—: Not investigated/stated

\section{Human health impacts of aflatoxins}

\begin{tabular}{|c|c|c|c|c|c|c|c|}
\hline \multirow[t]{2}{*}{ Region } & \multirow[t]{2}{*}{ Year } & \multirow[t]{2}{*}{ Commodity } & \multirow{2}{*}{$\begin{array}{c}\text { Number of } \\
\text { samples }\end{array}$} & \multirow[t]{2}{*}{ Positive samples (\%) } & \multicolumn{2}{|c|}{ Range ( $\mu \mathrm{g} / \mathbf{k g})$} & \multirow[t]{2}{*}{ Reference } \\
\hline & & & & & $\mathrm{AFB}_{1}$ & Total AFs & \\
\hline \multirow[t]{2}{*}{ Pakistan } & 2016 & Wheat & 18 & $12(67)$ & $0.04-6.7$ & $0.04-6.9$ & {$[22]$} \\
\hline & & Corn & 18 & $9(50)$ & $0.04-7.3$ & $0.04-8.1$ & \\
\hline Kenya & - & Maize & 338 & $320(95)$ & $1.69-403$ & $2.1-411$ & {$[25]$} \\
\hline \multirow[t]{3}{*}{ Somalia } & $2014-2015$ & Maize & 42 & $42(100)$ & $25.5-908.0$ & $28.3-1080.0$ & {$[26]$} \\
\hline & & Sorghum & 40 & $17(40)$ & $0.6-105.1$ & $0.6-105.0$ & \\
\hline & & Wheat & 58 & nd & nd & nd & \\
\hline Tunisia & $2011-2012$ & Sorghum & 64 & $38(59)$ & $0.03-31.7$ & - & [29] \\
\hline China & 2016 & Wheat & 32 & $7(22)$ & $0.04-0.12$ & - & {$[30]$} \\
\hline Vietnam & 2016 & Maize & 378 & $204(54)$ & $0.05-417.0$ & - & {$[31]$} \\
\hline
\end{tabular}

Since their discovery in 1960 following the "Turkey-X" disease that killed 100,000 turkeys in England, AFs have been considered as a major health risk worldwide [4,14]. Aflatoxicosis is a serious health problem that results from the consumption of infected grains [12]. Depending upon the level and duration of exposure, AFs can cause acute to chronic toxicity in humans $[4,11]$. Acute toxicity is a major problem in developing countries [4, 32]. Approximately 4 billion people residing in these countries are exposed to AFs, accounting for more than $40 \%$ of public health burden [12]. Symptoms are generally characterised by nausea, ataxia, loss of appetite, lethargy, liver inflammation, abdominal pain, jaundice, edema, coma, haemorrhage and even death in humans $[4,9,32]$. Chronic aflatoxicoisis is a global health concern that is associated with liver cancer, stunted growth, liver cirrhosis, hepatotoxicity, and immunosuppression [3, 9, 11,32]. A positive correlation between AFs and other health problems such as HIV [9], infertility in males, anaemia in pregnant women [33] hepatitis B, hepatitis C [34], hepatocellular carcinoma (HCC) and malnutrition [21] has been established.

HCC is a major consequence of AFs toxicity responsible for more than 320,000 incidences each year, making it the 3rd leading cause of cancer deaths reported globally, and the 7th and 9th major type of cancer in men and women, respectively [11, 16, 32]. Moreover, AFB1, the most toxic of all AFs, accounts for around $25 \%$ of the global HCC incidences annually $[14,21,35]$. Due to frequent occurrence of AFs in cereals and their detrimental effects on human and animal health, AFs have been closely monitored and regulated by United States Food and Drug Administration (US-FDA) since 1969 [4]. Furthermore, more than 120 countries have now established Maximum Limits (MLs) for AFs to safeguard human and animal health [32]. For example, within the EU, MLs of $4 \mu \mathrm{g} / \mathrm{kg}$ and $2 \mu \mathrm{g} / \mathrm{kg}$ have been set for sum of AFs $(\mathrm{B} 1+\mathrm{B} 2+\mathrm{G} 1+\mathrm{G} 2)$ and AFB1, respectively, in cereals and all products derived from cereals, including processed cereal products. Also, the US-FDA has established a limit of $20 \mu \mathrm{g} / \mathrm{kg}$ for AFB1 in all types of food [36]. Similarly, the Food Safety and Standards Authority of India (FSSAI) has imposed a maximum limit of $15 \mu \mathrm{g} / \mathrm{kg}$ for total AFs and $10 \mu \mathrm{g} / \mathrm{kg}$ for AFB1 in cereal and cereal products [37].

\section{Factors responsible for accumulation of Aflatoxins}


Several factors (intrinsic and extrinsic) promoting fungal growth and AFs production in cereals have been identified, as illustrated in Figure 1. Amongst these, temperature, relative humidity $(\mathrm{RH})$, moisture or water activity (aw), soil characteristics, $\mathrm{pH}$, nutrient availability, and insect damage are the major factors shown to be responsible for AFs contamination of cereals $[3,7,9,12,16,32-33,38-41]$. Two or more intrinsic or extrinsic factors as well as interactions among these factors can promote fungi growth and AFs production at any stage of the cereal supply chain [33]. The most important factors promoting Aspergillus growth and AFs biosynthesis are discussed below.

\subsection{Nutritional composition}

Nutrient availability is one of the most important intrinsic factors influencing the amount and rate of AFs production in cereals [33]. AFs synthesis is largely regulated by varying concentrations of carbon, nitrogen and trace elements present in grains. Simple sugars such as glucose, sucrose, fructose and maltose favour AFs production, whereas peptone, sorbose and lactose do not [33,41]. Also, several amino acids such as asparagine, aspartate, alanine, glutamate, and proline promote AFs biosynthesis, while it is suppressed by sodium nitrate and nitrite [34]. Liu et al. [42] analysed the effects of sugars, amino acids, lipids and trace elements on AFB1 synthesis in fat and defatted substrates (soybean, peanut, corn, wheat, corn endosperm and corn germ). Their results revealed that full fat substrates promoted higher biosynthesis of AFB1 compared to defatted substrates. Also, addition of corn oil to defatted substrates resulted in elevated production of AFB1. Additionally, while AFB1 production was also increased on increasing the concentrations of soluble sugars (glucose, maltose, sucrose, fructose, raffinose and stachyose) and trace elements $(\mathrm{Cu}, \mathrm{Fe}, \mathrm{Zn}$ and $\mathrm{Mn}$ ), AFs production was significantly reduced by high levels of amino acids [42]. A similar study by Ahmad et al. [43] also showed that high concentrations of carbon and nitrogen sources positively influenced AFs production. Overall, these studies show that substrates with high concentrations of nutrients such as lipids, sucrose, stachyose, glutamic acid and trace elements can highly influence AFs production; thus, can be altered especially during storage, processing, and transportation, to reduce the risk of fungal growth and AFs contamination.

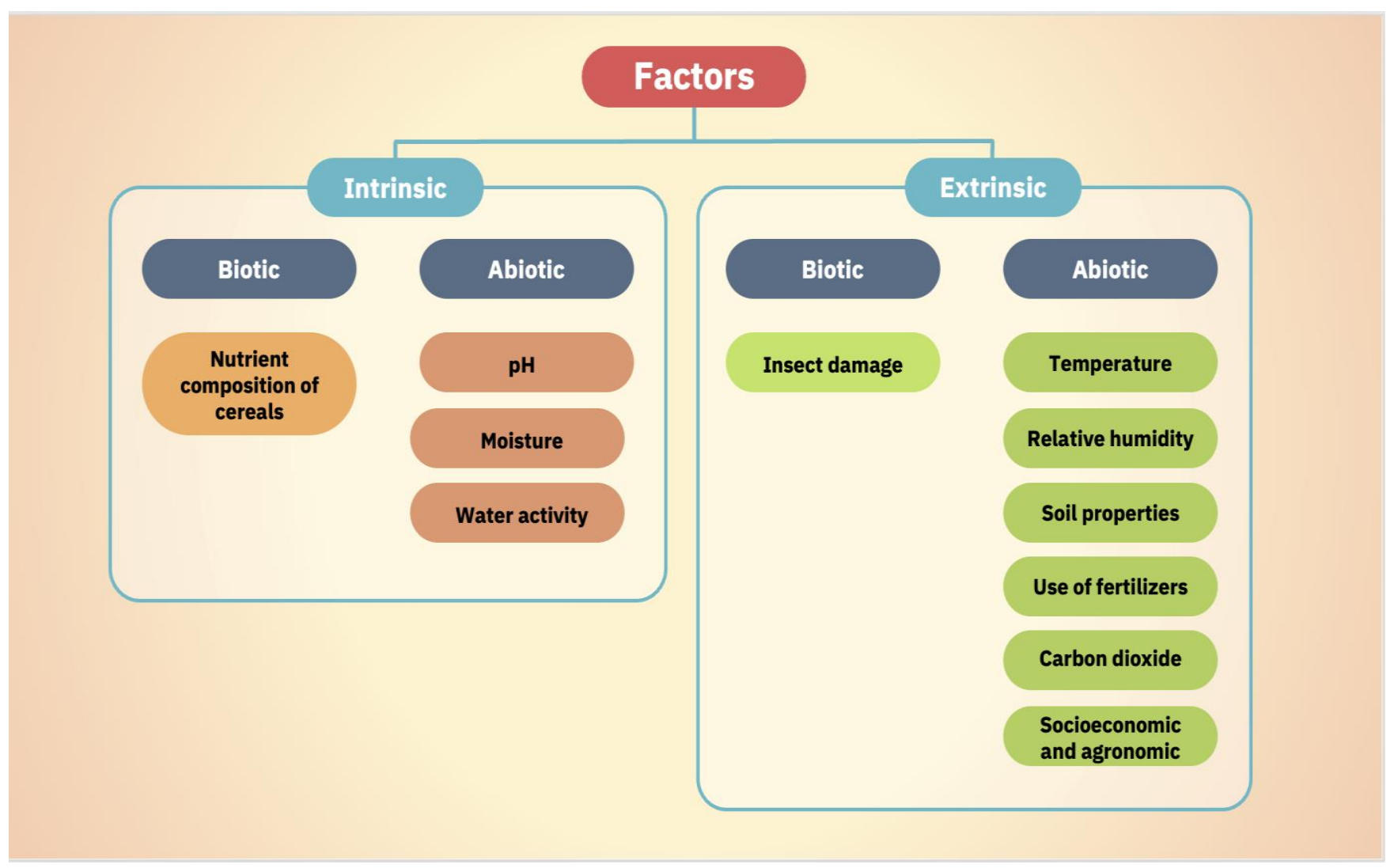

Figure 1. Key intrinsic and extrinsic factors promoting the growth of Aspergillus species and aflatoxins production in cereals.

\subsection{Environmental and climatic factors}


Environmental factors such as temperature, moisture content or aw and RH are majorly responsible for AFs contamination in stored grains. Amongst them, temperature and aw have a direct impact on the storability of the grains [16]. Extensive research has been conducted to evaluate the effects of their interactions on Aspergillus growth and subsequent AFs production in cereal crops. Jaibangyang et al. [44] studied the effects of storage conditions i.e., temperature $\left(25,30\right.$ and $\left.35^{\circ} \mathrm{C}\right)$ and $\mathrm{RH}(12 \%, 44 \%, 76 \%$ and $98 \%)$ on AFB1 synthesis in inoculated corn grains and recorded maximum concentration of $244.36 \pm 54.32 \mathrm{ng} / \mathrm{g}$ at $25^{\circ} \mathrm{C}$ and $98 \%$ RH. Similarly, Muga et al. [45] examined the impact of different temperature $\left(20^{\circ} \mathrm{C}\right.$ and $\left.30^{\circ} \mathrm{C}\right)$, moisture $(14 \%, 15 \%, 16 \%, 18 \%$ and $20 \%)$ and $\mathrm{RH}(60 \%$ and $90 \%)$ levels on AFs formation by A. flavus in inoculated stored maize kernels. They showed that temperature, RH and their interactions significantly $(\mathrm{p} \leq 0.05)$ affected AFs production, with higher levels of AFs detected at $30^{\circ} \mathrm{C}$ and $90 \% \mathrm{RH}$. In another study, Bernáldezet al. [46] analysed the impact of $\mathrm{aw}_{\mathrm{w}}$ and temperature interactions on the growth and AFB1 synthesis by A. flavus on a maize-based nutrient medium. The optimal conditions for growth of $\mathrm{A}$. flavus were 0.99 aw and $30^{\circ} \mathrm{C}$ and the highest production of $\mathrm{AFB} 1$ was recorded at $0.99 \mathrm{aw}$ and $25-30^{\circ} \mathrm{C}$. In addition to the above-mentioned factors, other parameters such as $\mathrm{pH}$ and $\mathrm{CO}_{2}$ can also influence the production of $\mathrm{AFs}$ by A. flavus. Regarding $\mathrm{pH}$, Kosegartenet al. [47] studied the growth response of $A$. flavus in a food model system under different $\mathrm{pH}$ levels (3.5, 5.0 and 6.5) and observed that increasing pH level from 3.5 to 6.5 resulted in rapid fungal growth rate. Also, Vijaylakshmiet al. [48] investigated the influence of different $\mathrm{pH}$ levels (4-10) as an important independent variable of Pulse Electric Process - a non-thermal method of food preservation that uses short pulses of electricity for microbial inactivation. Whilst maximum production of $\mathrm{AFs}$ was recorded at $\mathrm{pH} 10$ and $12, \mathrm{AFs}$ content was significantly reduced at an acidic $\mathrm{pH} \leq 4$. Moreover, at $\mathrm{pH} 7$, no significant change was observed in AFs content [48].

$\mathrm{CO}_{2}$ levels in the gaseous environment can also have a significant impact on AFs accumulation, particularly in stored commodities. Mousa et al. [10] studied the influence of different $\mathrm{CO}_{2}$ concentrations (20-80\%) on A. flavus growth and AFs production in paddy rice. Maximum concentration of $\mathrm{CO}_{2}$ investigated $(80 \%)$ significantly reduced fungal growth. Moreover, combined effect of water activity 0.98 aw and $\mathrm{CO}_{2}(20 \%$ and $80 \%)$ significantly reduced $A$. flavus growth and toxin production. Conversely, Gilbert et al. [49] showed that exposure of $A$. flavus to the forecasted $\mathrm{CO}_{2}$ concentration (650-1000 ppm), with high temperature $\left(37^{\circ} \mathrm{C}\right)$ and water stress, resulted in a relatively high expression of AFs regulatory (aflR) and structural (aflD) genes, which also positively correlated with high accumulation of AFB1. Similarly, interacting climatic factors $-37^{\circ} \mathrm{C} / 0.92 \& 0.95 \mathrm{a}_{\mathrm{w}} / 650 \& 1000 \mathrm{ppm}$ also favoured elevated production of AFB1 [50]. Taken together, results of these studies reveal that temperature, moisture, $\mathrm{pH}, \mathrm{RH}$ and $\mathrm{CO}_{2}$ exert significant influence on $A s-$ pergillus growth and AFs biosynthesis. Also, the impact of their interaction varies with the type of cereal grain. Therefore, the development of models predicting optimum conditions for fungal growth and AFs production in different types of cereals can help to control AFs-producing fungal species, especially during storage and transportation. This would represent an early warning system or important preventive strategy to manage post-harvest contamination of grains. A summary of studies on optimum conditions for AFs production in various commodities is outlined in Table 2.

Table 2. Optimum conditions for production of aflatoxins in cereals under different interacting climatic factors (water activity - $\mathrm{a}_{\mathrm{w}}$, temperature - $\mathrm{T}^{\circ} \mathrm{C}$, and carbon dioxide- $\mathrm{CO}_{2}$ ). 
-: Not investigated/stated

\subsection{Climate change}

Major climatic changes such as the global rise in temperature and changes in precipitation patterns due to increased emission of green-house gases have been shown to have profound effects on fungal growth, distribution, and severity of mycotoxins occurrence in cereal crops [56]. Based on climate change projection of IPCC, average annual temperatures will rise at an increased rate of $4^{\circ} \mathrm{C}$ by 2100 , while an approximate increase of $200 \mathrm{ppm}$ is expected in the atmospheric $\mathrm{CO}_{2}$ levels. Also, precipitation is projected to result in longer rainfall periods and drought stresses in the coming years [57]. These changes have been shown to have a direct influence on the geographic distribution of fungal species infecting cereal crops and mycotoxin patterns. For instance, Aspergillus species confined mostly to tropical and subtropical climatic areas have been reported in areas with temperate climates such as Europe [56]. Various climatic models have been developed to predict the impact of climate change on the prevalence of AFs in cereals. Warnatzschet al. [59] predicted an increase of $1-2.5^{\circ} \mathrm{C}$ in temperature and $0-4 \%$ reduction in annual rainfall in Northern, Central and Southern regions

\begin{tabular}{|c|c|c|c|c|c|c|}
\hline \multirow{2}{*}{$\begin{array}{l}\text { Commodity/ } \\
\text { Substrate }\end{array}$} & \multirow{2}{*}{$\begin{array}{c}\text { Aspergillus specie/ } \\
\text { strain }\end{array}$} & \multirow[t]{2}{*}{ Aflatoxin type } & \multicolumn{3}{|c|}{ Optimum conditions for aflatoxins production } & \multirow[t]{2}{*}{ References } \\
\hline & & & $\begin{array}{c}\text { Water activity } \\
\qquad\left(\mathbf{a}_{\mathbf{w}}\right)\end{array}$ & $\begin{array}{c}\text { Temperature } \\
\left({ }^{\circ} \mathrm{C}\right)\end{array}$ & Carbon dioxide & \\
\hline Maize & A. flavus NRRL 3357 & Aflatoxin B1 & 0.99 & $25-30$ & - & {$[51]$} \\
\hline Rice & $\begin{array}{c}\text { A. flavus (DISF15 and } \\
\text { DISF10) }\end{array}$ & Aflatoxin B1 \& B2 & 0.98 & 30 & $20 \%$ & {$[10]$} \\
\hline Maize & A. flavus NRRL 3357 & Aflatoxin B1 & 0.99 & 30 & $650 \mathrm{ppm}$ & [49] \\
\hline Rice & A. flavus YC-15 & Aflatoxin B1 & 0.96 & 28 & - & {$[52]$} \\
\hline Rice & A. flavus & Aflatoxin B1 \& B2 & 0.98 & 30 & - & [53] \\
\hline Wheat & $A$. flavus & Aflatoxin B1 & 0.98 & 30 & - & [54] \\
\hline Sorghum & $A$. flavus & Aflatoxin B1 & $0.97-0.99$ & 37 & - & [55] \\
\hline
\end{tabular}

of Malawi from periods between 2020-2049 and 2040-2069. It was anticipated that these changes will further result in the increased risk of AFB1 contaminations of maize crops in Malawi. It was further predicted that AFs levels in cereal crops grown in Southern and Central regions of Malawi will exceed the EU ML of $5 \mu \mathrm{g}$ AFB1 per kg. Similarly, an increased risk of AFB1 contamination of maize and wheat crops under the $+2{ }^{\circ} \mathrm{C}$ climate change scenario is expected in Europe (central and southern Spain, the south of Italy, Greece, northern and south-eastern Portugal, Bulgaria, Albania, Cyprus and European Turkey) within the next 100 years [60]. A more recent model developed by Van der Fels-Klerxet al. [61] also suggested an overall increase in mean concentrations of AFB1occurring in maize imported from Eastern Europe (Ukraine) to the Netherlands. Overall, climate change is expected to favour increasing AFs contamination of cereal crops. Therefore, development of climatic models to predict the emerging risk of AFs contamination in cereals will play an important role in the development of preventive and mitigation strategies at pre-harvest and harvest levels. Moreover, probabilistic models are needed to evaluate the impact of climate change on international trade and feed and food safety.

\subsection{Socioeconomic and agronomic factors}

Socioeconomic (farmer's knowledge and age) and agronomic factors (crop rotation, tillage, use of fertilisers, and storage conditions) are also important determinants of AFs contamination of crops. A study conducted by Njeruet al. [62] revealed that $48 \%$ farmers in the age range of $46-60$ years were significantly $(p<0.05)$ more aware of AFs contamination of food compared to the younger age groups. Additionally, AFs levels were also positively correlated with the use of 
diammonium phosphate (DAP) fertiliser. AFs levels in crops grown in Kenya were 3.9 times higher than Kenyan regulatory limits $(10 \mu \mathrm{g} / \mathrm{kg})$ where DAP was used for crop cultivation. Recently, Mbaawuaga et al. [63] also studied the effects of drying methods on AFs contamination of maize in Nigeria and reported that about $50 \%$ of the maize samples under sun drying contained AFs levels exceeding the EU ML $(4 \mu \mathrm{g} / \mathrm{kg})$. Thus, farmer's knowledge and the agricultural practices they employ can play a crucial role in the pre-and post-harvest management of AFs levels in cereal crops. Hence, training and awareness programmes, particularly for smallholder farmers in developing countries can help to prevent and mitigate risks of AFs contamination.

\section{Prevention and detoxification of aflatoxins}

AFs contamination of cereal grains is ubiquitous and unavoidable $[9,64]$. They not only pose risk to human and animal health but also result in huge economic losses. Therefore, it is important to manage their occurrence either by preventing them from getting into the supply chains or, at least, by reducing their levels to acceptable limits. Significant control of pre- and post-harvest AFs contamination is highly dependent on deep understanding of previously discussed intrinsic and extrinsic factors. Moreover, as contamination of agricultural commodities by AFs can occur at any stage of the food supply chain, a wide range of preventive and mitigation strategies have been proposed to reduce the level of contamination. Due to the complexity of AFs contamination, a single strategy has been shown to be ineffective to eliminate AFs; combination of different strategies is required to successfully control or prevent AFs in commodities [65]. The prevention of AFs contamination is generally divided into two: pre-harvest and post-harvest management. Pre-harvest control mainly focuses on in-field prevention of fungal infection, while post-harvest management prevents AFs production during storage and transportation.

\subsection{Pre-harvest control}

Management practices based on Good Agricultural Practice (GAP) and Good Manufacturing Practice (GMP) such as crop rotation, tillage, and proper planting and harvesting time have been shown to reduce infestation of toxigenic Aspergillus and AFs contamination in the field [5, 7, 9, 34, 65-68]. Besides the chemical fungicides and insecticides frequently used to prevent and control fungi growth, several antagonist agents including vanillin and its derivatives $-\mathrm{o}-$ vanillin (3-methoxysalicylaldehyde), and HMB (2-hydroxy-4-methoxybenzaldehyde) have been reported to inhibit fungi growth and subsequent biosynthesis of mycotoxins [69-70]. These antagonists are "Generally Recognized as Safe" (GRAS) and are widely used to inhibit foodborne pathogens in food chains including Aspergillus, Penicillium, and Cryptococcus species. They inhibit aflatoxigenic mold growth by damaging the integrity of cell membrane [70] and prevent AFs production [71-72]. Biocontrol is another pre-harvest approach for preventing AFs contamination. This strategy involves the use of biocontrol agents (BCAs) - mainly microbes, to reduce mycotoxin contamination of crops or suppress the growth of plant pathogens. The main mode of actions of BCAs include competition (competitively exclude mycotoxin producers in-field), mycoparasitism (direct attack on pathogenic fungi), antibiosis (production of metabolites such as lytic enzymes or antibiotics with capacity to suppress growth of plant pathogen) and colonization of plant by beneficial microbes to trigger a local or primary defense mechanism against pathogenic microorganisms [73]. Reductions in AFs contamination ranging from $67 \%$ to $99 \%$ have been reported following the incorporation of non-toxigenic strains of Aspergillus species into fields or seeds [74]. Various bacterial and yeast species have been investigated, but most of the success in the biological control of AFs have been achieved using competitive atoxigenic strains of $A$. flavus or $A$. parasiticus [74]. Several formulations of these bio-control agents are now widely used and generally considered environmentally friendly and sustainable alternative to the chemical control agents. For instance, Afla-Guard and AF36 are formulations containing atoxigenic strain of A. flavus marketed in USA, to control AFs in peanut, maize and cottonseed [75]. Aflasafe is another commercial product containing four non-toxigenic strains of A. flavus of Nigerian origin. This product has gained approval to be commercialised in Africa [76]. AF-X1, a commercial bio-control product with nontoxigenic MUCL54911 strain of A. flavus is under registration to be used in maize in Italy [77].

Planting of resistant varieties is another prominent approach for preventing fungal invasion and mycotoxin contamination. Research advances in microarrays, fungal expressed sequence tags (EST), and whole genome sequencing have led to the identification of resistance-related genes involved in defence response against Aspergillus infection and AFs contamination [78]. These genes have been used to develop germplasm and cultivars with improved resistance [79]. For instance, a genetically modified maize expressing a high degree of anti-insecticidal gene significantly reduced AFs levels in maize [80]. However, most transgenic plants developed to date for increased resistance against pathogenic fungi and mycotoxin contamination only showed great efficiency under controlled laboratory or greenhouse environments, with little success in-field. Moreover, there are currently no commercially acceptable AFs resistant cultivars [81]. 


\subsection{Post-harvest control}

When control or prevention is not achievable at field level or during harvest, decontamination measures based on physical, chemical, and biological treatment of contaminated grains can be used post-harvest. Physical processes involve washing, polishing, density segregation, dehulling, milling, mechanical sorting and floating as well as irradiation, heat and cold plasma treatment [70]. Hand sorting is one of the most prominent and efficient process of decontamination in cereal grains, especially in developing countries [16]. Optical sorting using Bühler Lumovision ${ }^{\mathrm{TM}}$ is a new technology able to identify contaminated grains based on certain indicators of AFs contamination, while simultaneously using realtime cloud-based data to monitor and analyse contamination risk. This technology analyses the colour of each kernel fluoresces as it passes under UV lighting in the sorter. Contaminated kernels with bright green fluorescent are automatically removed from the product stream [70].

Mycotoxin-adsorbing agents has not much been utilised so far for AFs decontamination in food chains, but widely used as feed additives by feed processors and farmers for reducing AFs levels in feed. Adsorbents aim to prevent the absorption of mycotoxins from the gastro-intestinal tract of livestock animals by adsorbing the toxins to their surface to form a mycotoxin-binder complexes [82-83]. The bound mycotoxins are then excreted with the animal faeces. The efficiency of adsorbents to bind mycotoxins in feed is dependent on the origin and physicochemical properties [82]. The mechanism of action for sequestering mycotoxins includes hydrophobic binding, hydrogen bonds, electrostatic attraction or repulsion and coordination bonds [84]. The use of thermal process, such as roasting and extrusion has also been shown to be effective in eliminating AFs in corn, peanut, and coffee beans [85-86]. Microwave heating was found to be slightly more effective (5-8\%) than conventional heating to eliminate AFB1 [87] Radiation treatments including ultraviolet rays, gamma rays, electron beam irradiation and solar radiation have also been shown to be efficient for reducing AFs [8790]. Chemical detoxification involves treatment with hydrolases (acids or alkalis), oxidizing agents such as hydrogen peroxide and gases including ammonia and ozone. Among these, ozone plays an important role in mycotoxin degradation in food chains. It is approved by Food and Drug Administration and Food and Agriculture Organization as an antimicrobial agent for food treatment [91]. Application of ozone for AFs decontamination has been investigated in a variety of food products [92-94]. Ozonolysis reduces AFs in food through an electrophilic attack on C8-C9 double bond of the furan ring in AFs molecules, resulting in the formation of aldehydes, ketones, and organic acids [95]. Nevertheless, only a limited number of the physical and chemical measures are effective for reducing the levels of AFs without diminishing the feed nutritional value or palatability. Furthermore, the partial knowledge about degradation products and organoleptic changes limits their applications [96].

Biological detoxification of mycotoxins has been shown to be the most promising method due to its environmentally friendly nature. It can be achieved by using microorganisms or their enzymes to degrade or detoxify mycotoxins [5, 7, 11, 13, 21]. Several Aspergillus species, such as A. parasiticus, A. flavus and A. niger, have the potential to convert AFs (particularly AFB1) into a less toxic substance [97]. Also, several strains of Bacillus species have been extensively investigated for the detoxification of AFs [7, 98-99]. B. subtilis ANSB060 isolated from fish gut was demonstrated to rapidly degrade AFs [101-102]. Similarly, Petchkongkaew et al. [103] also showed that B. subtilis isolated from Thai fermented foods had a strong capability to degrade AFB1 when compared with other strains. Extracellular fraction of $B$. licheniformis CFR1 was also found to reduce AFB1 and contributed to the loss of AFB1 mutagenicity [21]. A strain of marine B. megaterium isolated from the Yellow Sea of East China was evaluated as an antagonist to prevent postharvest decay of peanut kernels caused by A. flavus. The isolate significantly inhibited AFs biosynthesis and the expression of aflR and aflS genes [104]. Nevertheless, degradation times of microorganism-mediated processes are very long, usually requiring several days to perform. Thus, use of purified enzymes isolated from biological sources are preferred for AFs degradation. Numerous enzymes such as laccases [105], manganese peroxidase [106-108], and aflatoxin oxidase [105], have been shown to detoxify AFs in food products. Laccases and peroxidases bio-transform AFs to less-toxic products by cleavage of the lactone ring, while aflatoxin oxidase detoxifies by opening up the difuran ring [105-108]. Current pre-and postharvest methods for AFs control and prevention are summarized in Figure 2. 


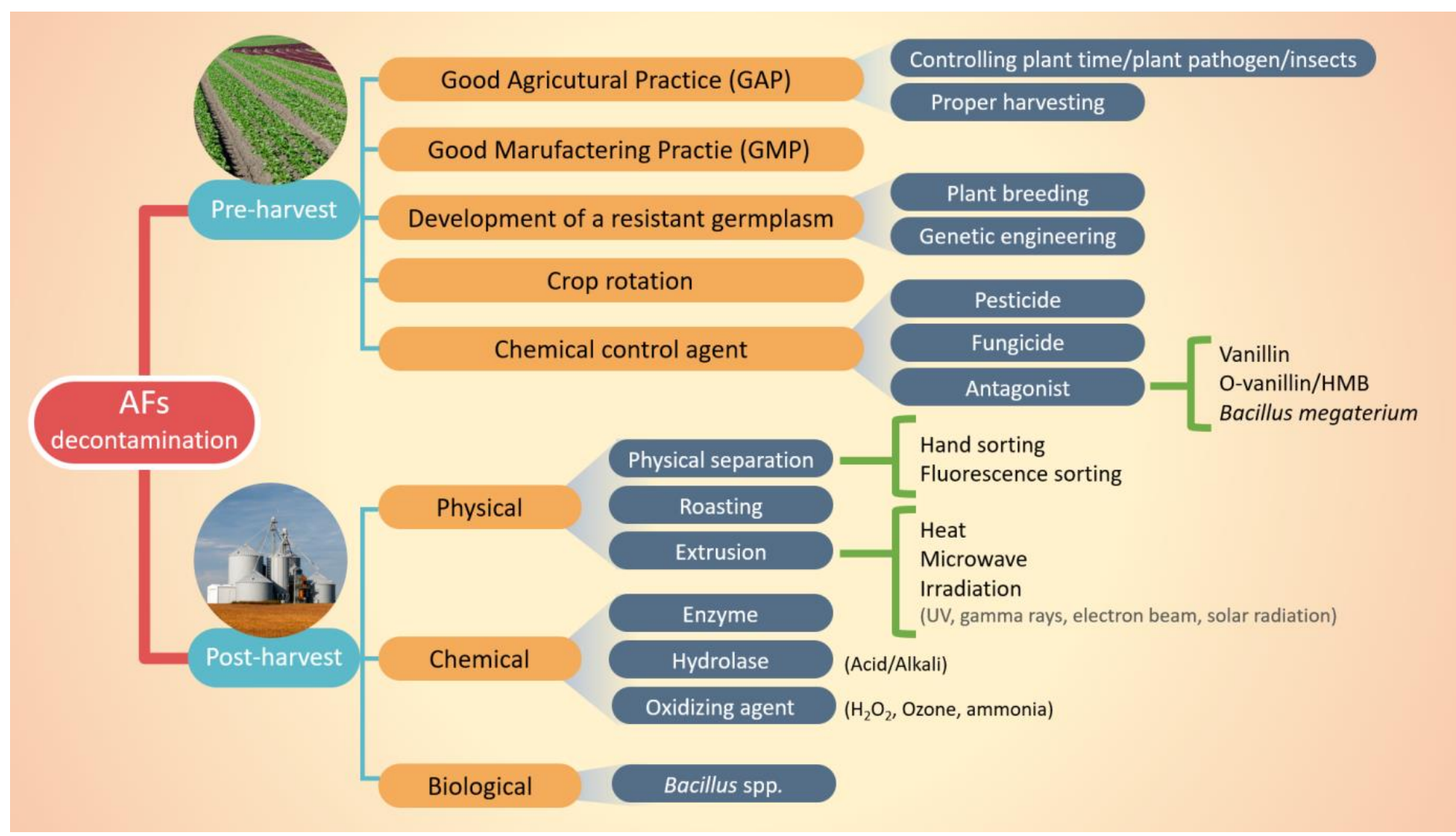

Figure 2. Pre-and post-harvest methods for prevention and control of aflatoxins in cereals

\section{Conclusion}

To recapitulate, AFs contamination of cereals is ubiquitous and unavoidable. These toxic metabolites cannot be eliminated by regular processing and therefore preventive strategies are needed to control their occurrence. Several intrinsic and extrinsic factors can favour AFs biosynthesis at pre- and post-harvest level. Amongst all favouring factors, nutritional composition, environmental factors (temperature, $\mathrm{a}_{\mathrm{w}}$ and $\mathrm{RH}$ ) and climate change have been identified as the primary factors, while $\mathrm{pH}$ of the substrate, $\mathrm{CO}_{2}$ levels in the gaseous environment, socioeconomic and agronomic determinants are the main secondary factors influencing AFs production in cereals. Further field studies are needed to fully comprehend the impact of each factor as well as their interactions on Aspergillus growth and production of AFs. This would improve our current understanding and enable the development of an effective preventive and control measures.

Funding: This research was funded by Thailand Science Research and Innovation Fundamental Fund [Project no. 2461863]

Acknowledgments: Acknowledgement is given to the Center of Excellence in Food Science and Innovation, Faculty of Science and Technology, Thammasat University for their support.

Conflicts of Interest: The authors declare no conflict of interest. The funders had no role in the design of the study; in the collection, analyses, or interpretation of data; in the writing of the manuscript, or in the decision to publish the results.

\section{References}

1. Kolawole, O.; DeRuyck, K.; Greer, B.; Meneely, J.; Doohan, F.; Danaher, M.; Elliott. Agronomic Factors Influencing the Scale of Fusarium Mycotoxin Contamination of Oats. J. Fungi. 2021, 7, 965. https://doi.org/10.3390/jof7110965

2. Sowley, E.N.K. Aflatoxins: a silent threat in developing countries. African Journal of Biotechnology. 2016, 15(35), 1864-1870.

3. Eskola, M.; Kos, G.; Elliott, C.T.; Hajšlová, J.; Mayar, S.; Krska, R. Worldwide contamination of food-crops with mycotoxins: Validity of the widely cited 'FAO estimate' of 25\%. Critical Reviews in Food Science and Nutrition. 2020, 60, 2773-2789. 
4. Alshannaq, A.; Yu, J.H. Occurrence, toxicity, and analysis of major mycotoxins in food. International Journal of Environmental Research and Public Health. 2017, 14, 632. https://doi.org/10.3390/ijerph14060632

5. Bhatnagar, D.; Brown, R.; Ehrlich, K. Cleveland, T.E. Mycotoxins contaminating cereal grain crops: their occurrence and toxicity. Applied Mycology and Biotechnology. 2002, 2, 171-196. https://doi.org/10.1016/S1874-5334(02)80010-7

6. Wan, J.; Chen, B.; Rao. J. Occurrence and preventive strategies to control mycotoxins in cereal-based food. Comprehensive Reviews in Food Science and Food Safety. 2020, 19, 928-953. https://doi.org/10.1111/1541-4337.12546

7. Marshall, H.; Meneely, J.P.; Quinn, B.; Zhao, Y.; Bourke, P.; Gilmore, B.F.; Zhang, G.; Elliott, C.T. Novel decontamination approaches and their potential application for post-harvest aflatoxin control. Trends in Food Science \& Technology. 2020.

https://doi.org/10.1016/j.tifs.2020.11.001

8. Kolawole, O.; Graham, A.; Donaldson, C.; Owens, B.; Abia, W.; Meneely, J.; Alcorn, M.; Connolly, L.; Elliott, C. Low Doses of Mycotoxin Mixtures below EU Regulatory Limits Can Negatively Affect the Performance of Broiler Chickens: A Longitudinal Study. Toxins. 2020, 12, 433.

9. MousaviKhaneghah, A.; Eş, I.; Raeisi, S.; Fakhri, Y. Aflatoxins in cereals: State of the art. Journal of Food Safety. 2018, 38 , e12532. https://doi.org/10.1111/jfs.12532

10. Mousa, W.; Ghazali, F.M.; Jinap, S.; Ghazali, H.M.; Radu, S.; Salama, A.E.R. Temperature, water activity and gas composition effects on the growth and aflatoxin production by Aspergillus flavus on paddy. Journal of Stored Products Research. 2016, 67, 49-55. https://doi.org/10.1016/j.jspr.2016.01.003

11. Ismail, A.; Gonçalves, B.L.; De Neeff, D.V.; Ponzilacqua, B.; Coppa, C.F.; Hintzsche, H.; Sajid, M.; Cruz, A.G.; Corassin, C.H.; Oliveira, C.A. Aflatoxin in foodstuffs: Occurrence and recent advances in decontamination. Food Research International. 2018, 113, 74-85. https://doi.org/10.1016/j.foodres.2018.06.067

12. Nazhand, A.; Durazzo, A.; Lucarini, M.; Souto, E.B.; Santini, A. Characteristics, occurrence, detection and detoxification of aflatoxins in foods and feeds. Foods. 2020, 9, 644. https://doi.org/10.3390/foods9050644

13. Dors, G.C.; Caldas, S.S.; Feddern, V.; Bemvenuti, R.H.; Hackbart, H.C.S.; Souza, M.M.; Oliveira, M.S.; Buffon, J.G.; Primel, E.; Furlong, E.B. Aflatoxins: contamination, analysis and control. Available online:

https:/www.alice.cnptia.embrapa.br/bitstream/doc/907418/1/InTechAflatoxinscontaminationanalysisandcontrol.pdf (accessed on 20 December 2020).

14. Lee, H.J.; Ryu, D. Worldwide Occurrence of Mycotoxins in Cereals and Cereal-derived food products: public health perspectives of their co-occurrence', Journal of Agricultural and Food Chemistry. 2017, 65, 7034-7051. http://dx.doi.org/10.1021/acs.jafc.6b04847

15. International Agency of Research on Cancer (IARC). Some traditional herbal medicines, some mycotoxins, napohthalene and styrene. IARC Monograpghs on the Evaluation of Carcinogenic Risks to Human. 2002, 82, 1-556.

16. Neme, K.; Mohammed, A. Mycotoxin occurrence in grains and the role of postharvest management as a mitigation strategies. A review. Food Control. 2017, 78, 412-425. https://doi.org/10.1016/j.foodcont.2017.03.012

17. McKevith, B. Nutritional aspects of cereals. Nutrition Bulletin. 2014, 29, 111-142. https://doi.org/10.1111/j.1467-3010.2004.00418.x

18. Food Agriculture Organisation. Chapter 3. Cereals, Available online: http://www.fao.org/3/CA4076EN/CA4076EN Chapter3 Cereals.pdf (accessed on 29 March 2021).

19. Khodaei, D.; Javanmardi, F.; Khaneghah, A.M. The global overview of the occurrence of mycotoxins in cereals: a three-year survey. Current Opinion in Food Science. 2021, 39, 36-42. https://doi.org/10.1016/j.cofs.2020.12.012

20. Ismail, A.; Riaz, M.; Gong, Y.Y.; Akhtar, S.; Sun, J. Aflatoxins in plant-based foods. Plant and Human Health, ed.; Ozturk, M. and Hakeem, K.; Springer, Cham, 2020; Volume 2, pp. 313-325. 
21. Rushing, B.R.; Selim, M.I. Aflatoxin B1: A review on metabolism, toxicity, occurrence in food, occupational exposure, and detoxification methods. Food and Chemical Toxicology. 2019, 124, 81-100. https://doi.org/10.1016/j.fct.2018.11.047

22. Alim, M.; Iqbal, S.Z.; Mehmood, Z.; Asi, M.R.; Zikar, H.; Chanda, H.; Malik, N. Survey of mycotoxins in retail market cereals, derived products and evaluation of their dietary intake. Food Control. 2018, 84, 471-477. https://doi.org/10.1016/j.foodcont.2017.08.034

23. Daou, R.; Joubrane, K.; Khabbaz, L.R.; Maroun, R.G.; Ismail, A.; El Khoury, A. Aflatoxin B1 and ochratoxin A in imported and Lebanese wheat and-products. Food Additives \& Contaminants: Part B. 2021, 14, 1-9. https://doi.org/10.1080/19393210.2021.1933203

24. Iqbal, S.Z.; Asi, M.R.; Hanif, U.; Zuber, M.; Jinap, S. The presence of aflatoxins and ochratoxin A in rice and rice products and evaluation of dietary intake. Food Chemistry. 2016, 210, 135-140.

https://doi.org/10.1016/j.foodchem.2016.04.104

25. Nabwire, W.R.; Ombaka, J.; Dick, C.P.; Strickland, C.; Tang, L.; Xue, K.S.; Wang, J.S. Aflatoxin in household maize for human consumption in Kenya, East Africa. Food Additives \& Contaminants: Part B. 2020, 13, 45-51. https://doi.org/10.1080/19393210.2019.1690053

26. Wielogorska, E.; Mooney, M.; Eskola, M.; Ezekiel, C.N.; Stranska, M.; Krska, R.; Elliott, C. Occurrence and human-health impacts of mycotoxins in Somalia. Journal of Agricultural and Food Chemistry. 2019, 67, 2052-2060. https://doi.org/10.1021/acs.jafc.8b05141

27. Tarazona, A.; Gómez, J.; Mateo, F.; Jiménez, M.; Romera, D.; Mateo, E. Study on mycotoxin contamination of maize kernels in Spain. Food Control. 2019, 118, 107370 .

28. Worku, A.; Merkuz, A.; Kalsa, K.; Tenagashaw, M.; Habtu, N. Occurrence of mycotoxins in farm-stored wheat in Ethiopia. African Journal of Food Agriculture Nutrition and Development. 2019, 19, 14829-14847.

29. Lahouar, A.; Marin, S.; Crespo-Sempere, A.; Saïd, S.; Sanchis, V. Effects of temperature, water activity and incubation time on fungal growth and aflatoxin B1 production by toxinogenic Aspergillus flavus isolates on sorghum seeds. Revista Argentina de Microbiologia. 2016, 48, 78-85. https://doi.org/10.1016/j.ram.2015.10.001

30. Zhao, Y.; Wang, Q.; Huang, J.; Ma, L.; Chen, Z.; Wang, F. Aflatoxin B1 and sterigmatocystin in wheat and wheat products from supermarkets in China. Food Additives \& Contaminants: Part B. 2017, 11, 9-14.

31. Nguyen, X.; Nguyen, T.; Nguyen-Viet, H.; Tran, K.; Lindahl, J.; Grace Randolph, D.; Ha, T.; Lee, H. Assessment of aflatoxin B1 in maize and awareness of aflatoxins in Son La, Vietnam. Infection Ecology \& Epidemiology. 2018, 8, p.1553464.

32. Pratiwi, C.; Rahayu, W. P.; Lioe, H. N.; Herawati, D.; Broto, W.; Ambarwati, S. The effect of temperature and relative humidity for Aspergillus flavus BIO 2237 growth and aflatoxin production on soybeans. International Food Research Journal. 2015, 22, 82-87.

33. Achaglinkame, M.A.; Opoku, N.; Amagloh, F.K. Aflatoxin contamination in cereals and legumes to reconsider usage as complementary food ingredients for Ghanaian infants: A review. Journal of Nutrition E Intermediary Metabolism. 2017, 10, 1-7. https://doi.org/10.1016/j.jnim.2017.09.001

34. Yu, J. Current understanding on aflatoxin biosynthesis and future perspective in reducing aflatoxin contamination. Toxins. 2012, 4, 10241057. https://doi.org/10.3390/toxins4111024.

35. Valencia-Quintana, R.; Milić, M.; Jakšić, D.; ŠegvićKlarić, M.; Tenorio-Arvide, M.G.; Pérez-Flores, G.A.; Bonassi, S.; Sánchez-Alarcón, J. Environment changes, aflatoxins, and health Issues, a review. International Journal of Environmental Research and Public Health. 2020, 17, 7850. https://doi.org/10.3390/ijerph17217850

36. Food and Drug Administration (FDA). Guidance for Industry: action levels for poisonous or deleterious substances in human food and animal feed. 2018. Available online: https://www.fda.gov/regulatory-information/search-fda-guidance-documents/guidance-industryaction-levels-poisonous-or-deleterious-substances-human-food-and-animal-feed\#afla(Accessed on 30 March 2021).

37. Food Safety and Standards Authority of India (FSSAI). Food safety and standards (contaminants, toxins and residues) regulations. Available online:

https://www.fssai.gov.in/upload/uploadfiles/files/Compendium_Contaminants_Regulations_20_08_2020.pdf 
(accessed 4 October 2021).

38. Kolawole, O.; Meneely, J.; Petchkongkaew, A.; Elliott, C. A review of mycotoxin biosynthetic pathways: associated genes and their expressions under the influence of climatic factors. Fungal Biology Reviews. 2021, 37, 8-26.

39. Moretti, A.; Pascale, M.; Logrieco, A.F. Mycotoxin risks under a climate change scenario in Europe. Trends in Food Science E Technology. 2019, 84, 38-40. https://doi.org/10.1016/j.tifs.2018.03.008

40. Milani, J.M. Ecological conditions affecting mycotoxin production in cereals: a review. Veterinarni Medicina. 2013. 58, 405-411. doi.org/10.17221/6979-VETMED

41. Wang, P.; Chang, P.K.; Kong, Q.; Shan, S.; Wei, Q. Comparison of aflatoxin production of Aspergillus flavus at different temperatures and media: Proteome analysis based on TMT'. International Journal of Food Microbiology. 2019, 34, 108-313. https://doi.org/10.1016/j.ijfoodmicro.2019.108313

42. Liu, J.; Sun, L.; Zhang, N ;, Zhang, J.; Guo, J.; Li, C.; Rajput, S.A; Qi, D. Effects of nutrients in substrates of different grains on aflatoxin B1 production by Aspergillus flavus. BioMed Research International. 2016. doi.org/10.1155/2016/7232858

43. Ahmad, M.; Ahmad, M.M.; Hamid, R.; Abdin, M.Z.; Javed, S. Use of response surface methodology to study the effect of media composition on aflatoxin production by Aspergillus flavus. Mycotoxin Research. 2013, 29, 39-45. doi 10.1007/s12550-012-0151-x.

44. Jaibangyang, S.; Nasanit, R.; Limtong, S. Effects of temperature and relative humidity on Aflatoxin B1 reduction in corn grains and antagonistic activities against Aflatoxin-producing Aspergillus flavus by a volatile organic compound-producing yeast, Kwoniellaheveanensis DMKU-CE82. BioControl. 2021, 1-11.

45. Muga, F.C.; Marenya, M.O.; Workneh, T.S. Effect of temperature, relative humidity and moisture on aflatoxin contamination of stored maize kernels. Bulgarian Journal of Agricultural Science. 2019, 25, 271-277.

46. Bernáldez, V.; Córdoba, J.J.; Magan, N.; Peromingo, B.; Rodríguez, A. The influence of ecophysiological factors on growth, aflR gene expression and aflatoxin B1 production by a type strain of Aspergillus flavus. LWT - Food Science and Technology. 2017, 83, $283-291$.

http://dx.doi.org/10.1016/j.1wt.2017.05.030

47. Kosegarten, C. E.; Ramírez-Corona, N.; Mani-López, E.; Palou, E.; López-Malo, A. Description of Aspergillus flavus growth under the influence of different factors (water activity, incubation temperature, protein and fat concentration, $\mathrm{pH}$, and cinnamon essential oil concentration) by kinetic, probability of growth, and time-to-detection models International Journal of Food Microbiology. 2017, 240, 115-123. https://doi.org/10.1016/j.ijfoodmicro.2016.04.024

48. Vijayalakshmi, S.; Nadanasabhapathi, S.; Kumar, R.; Kumar, S.S. Effect of $\mathrm{pH}$ and pulsed electric field process parameters on the aflatoxin reduction in model system using response surface methodology. Journal of Food Science and Technology. 2018, 55, 868-878. https://doi.org/10.1007/s13197-017-2939-3

49. Gilbert, M.; Medina, A.; Mack, B.; Lebar, M.; Rodríguez, A.; Bhatnagar, D.; Magan, N.; Obrian, G.; Payne, G. Carbon Dioxide Mediates the Response to Temperature and Water Activity Levels in Aspergillus flavus during Infection of Maize Kernels. Toxins. 2017, 10, p.5.

50. Gilbert, M.K.; Mack, B.M.; Payne, G.A.; Bhatnagar, D. Use of functional genomics to assess the climate change impact on Aspergillus flavus and aflatoxin production. World Mycotoxin Journal. 2016, 9, 665-672. https://doi.org/10.3920/WMT2016.2049

51. Gallo, A.; Solfrizzo, M.; Epifani, F.; Panzarini, G.; Perrone, G. Effect of temperature and water activity on gene expression and aflatoxin biosynthesis in Aspergillus flavus on almond medium. Int J Food Microbiol. 2016, 217, 162-169.

52. Lv, C.; Jin, J.; Wang, P.; Dai, X.; Liu, Y.; Zheng, M.; Xing, F. Interaction of water activity and temperature on the growth, gene expression and aflatoxin production by Aspergillus flavus on paddy and polished rice. Food Chemistry. 2019, 293, 472-478. https://doi.org/10.1016/j.foodchem.2019.05.009

53. Nandi, B; Häggblom, P. Production of Aflatoxin in Rough Rice under Different Storage Conditions. Acta Agriculturae Scandinavica. 2009, 34, 128-132. 
54. Hassane, A.M.A.; El-Shanawany, A.A.; Abo-Dahab, N.F.; Abdel-Hadi, A.M.; Abdul-Raouf, U.M.; Mwanza, M. Influence of different moisture contents and temperature on growth and production of aflatoxin B1 by a toxigenic Aspergillus flavus isolate in wheat flour. Journal of Ecology of Health \& Environment. 2017, 5, 77-83. http://dx.doi.org/10.18576/jehe/050302

55. Lahouar, A.; Marin, S.; Crespo-Sempere, A.; Saïd, S.; Sanchis, V. Effects of temperature, water activity and incubation time on fungal growth and aflatoxin B1 production by toxinogenic Aspergillusflavus isolates on sorghum seeds. Revista Argentina de Microbiologia. 2016, 48, 78-85. doi.org/10.1016/j.ram.2015.10.001

56. Van der Fels-Klerx, H.J.; Liu, C.; Battilani, P. Modelling climate change impacts on mycotoxin contamination. World Mycotoxin Journal. 2016, 9(5), 717-726. https://doi.org/10.3920/WMI2016.2066

57. Van der Fels-Klerx, H.J.; Vermeulen, L.C.; Gavai, A.K.; Liu, C. Climate change impacts on aflatoxin B1 in maize and aflatoxin M1 in milk: A case study of maize grown in Eastern Europe and imported to the Netherlands. PLoS One. 2019, 14, e0218956. https://doi.org/10.1371/journal.pone.0218956

58. Medina, Á.; Rodríguez, A.; Sultan, Y.; Magan, N. Climate change factors and Aspergillus flavus: effects on gene expression, growth and aflatoxin production. World Mycotoxin J. 2015, 8, 171-179.

59. Warnatzsch, E.A.; Reay, D.S.; Camardo Leggieri, M.; Battilani, P. Climate change impact on aflatoxin contamination risk in Malawi's maize crops. Frontiers in Sustainable Food Systems. 2020, 4, 238. https://doi.org/10.3389/fsufs.2020.591792

60. Battilani, P.; Toscano, P.; Van der Fels-Klerx, H.J.; Moretti, A.; Leggieri, M.C.; Brera, C.; Rortais, A.; Goumperis, T.; Robinson, T. Aflatoxin B1 contamination in maize in Europe increases due to climate change. Scientific Reports. 2016, 1-7. https://doi.org/10.1038/srep24328

61. Van der Felx-Klers, H.J.; Dekkers, S.; Kandhai, M. C.; Jeurissen, S.M.F.; Booij, C.J.H. Indicators for early identification of re-emerging mycotoxin. Journal of Life Sciences. 2010, 57, 133-139.

62. Njeru, N.K.; Midega, C.A.O.; Muthomi, J.W.; Wagacha, J.M.; Khan, Z.R. Influence of socio-economic and agronomic factors on aflatoxin and fumonisin contamination of maize in western Kenya. Food Science \& Nutrition. 2019, 7, 2291-2301. https://doi.org/10.1002/fsn3.1070

63. Mbaawuaga, E.M.; Nwabude, J.O; Shiriki, D. Effects of farmers' practices on maize (Zea mays) contamination by potential aflatoxigenic fungi and aflatoxin in Benue State, Nigeria. Agricultural Sciences. 2020, 11, 500-513. https://doi.org/10.4236/as.2020.115031

64. Wan, J.; Chen, B.; Rao. J. Occurrence and preventive strategies to control mycotoxins in cereal-based food. Comprehensive Reviews in Food Science and Food Safety. 2020,19, 928-953.:https://doi.org/10.1111/1541-4337.12546

65. Torres, A. M.; Barros, G. G.; Palacios, S. A.; Chulze, S. N.; Battilani, P. Review on pre- and post-harvest management of peanuts to minimize aflatoxin contamination. Food Research International. 2014, 62, 11-19. doi:https://doi.org/10.1016/j.foodres.2014.02.023

66. Ortiz, M. P.; Barros, G. G.; Reynoso, M. M.; Torres, A.M.; Chulze, S. N.; Ramirez, M. L. Soil populations of Aspergillus section Flavi from the main and new peanut growing areas in Argentina. ISM Conference "Strategies to reduce the impact of mycotoxins in Latin America in a global context". Abstract Book. 2011.

67. Codex Alimentarius Commission - CAC. Code of Practice for the prevention and reduction of aflatoxin contamination in peanuts. CAC/RCP. 2004, 55 .

68. Bruns, H. A. Controlling Aflatoxin and Fumonisin in Maize by Crop Management. Journal of Toxicology Toxin Reviews. 2003, $22,153-173$. https://doi.org/10.1081/TXR-120024090

69. Kabak, B. Dobson, A. D.; Var, I. Strategies to prevent mycotoxin contamination of food and animal feed: a review. Crit Rev Food Sci Nutr. 2006, 46, 593-619. doi:10.1080/10408390500436185

70. Li, Q.; Zhu, X. Vanillin and its derivatives, potential promising antifungal agents, inhibit Aspergillus flavus spores via destroying the integrity of cell membrane rather than cell wall. Grain \& Oil Science and Technology. 2021, 34, 15-26. doi:https://doi.org/10.1016/j.gaost.2021.03.002 
71. Harohally, N. V.; Cherita, C.; Bhatt, P.; Anu Appaiah, K. A. Antiaflatoxigenic and Antimicrobial Activities of Schiff Bases of 2-Hydroxy-4methoxybenzaldehyde, Cinnamaldehyde, and Similar Aldehydes. J Agric Food Chem. 2017, 65, 8773-8778. doi:10.1021/acs.jafc.7b02576

72. Li, Q.; Zhu, X.; Xie, Y.; Ren, S. R Hydrox ${ }^{\mathrm{TM}} 4$ methoxybenzaldehyde inhibits the growth of Aspergillus flavus via damaging cell wall, cell membrane, manipulating respiration thus creating a promising antifungal effect on corn kernels. International Journal of Food Science and Technology. 2020, 45, 2 -35

73. Saleh, A.; Ul-Hassan, Z.; Zeidan, R.; Al-Shamary, N.; Al-Yafei, T.; Alnaimi, H.; Higazy, N.; Migheli, Q.; Jaoua, S. Biocontrol Activity of Bacillus megaterium BM344-1 against Toxigenic Fungi. ACS Omega. 2021, 6, 10984-10990.

74. Mwakinyali, S.E.; Ding, X.; Ming, Z.; Tong, W.; Zhang, Q.; Li, P. Recent development of aflatoxin contamination biocontrol in agricultural products. Biological Control. 2019, 128, 31-39. https://doi.org/10.1016/j.biocontrol.2018.09.012

75. Dorner, J.W. Biological control of aflatoxin contamination in corn using a nontoxigenic strain of Aspergillus flavus. Journal of Food Protection. 2019, 74, 801-804. https://doi.org/10.4315/0362-028x-72.4.801

76. Hell, K.; Mutegi, C. Aflatoxin control and prevention strategies in key crops of Sub-Saharan Africa, African Journal of Microbiology Research. 2011, 5, 459-466.

77. Mauro, A.; Garcia-Cela, E.; Pietri, A.; Cotty, P.J.; Battilani, P. Biological control products for aflatoxin prevention in Italy: Commercial field evaluation of atoxigenic Aspergillus flavus active Ingredients. Toxins. 2018, 10, 30 https://doi.org/10.3390/toxins10010030

78. Prasad, K.; Sharma, K.K.; Bhatnagar-Mathur, P. Biotechnological Strategies for Development of Aflatoxin-Free Crops. Nutritional Quality Improvement in Plants. 2019, 14, 289-376. https://doi.org/10.1007/978-3-319-95354-0_11

79. Bhatnagar-Mathur, P.; Sunkara, S.; Bhatnagar-Panwar, M.; Waliyar, F.; Sharma, K.K. Biotechnological advances for combating Aspergillus flavus and aflatoxin contamination in crops. Plant Science. 2015, 119-132. https://doi.org/10.1016/j.plantsci.2015.02.009

80. Weaver, M.; Abbas, H.; Brewer, M.; Pruter, L.; Little, N. Integration of biological control and transgenic insect protection for mitigation of mycotoxins in corn. Crop Protection. 2017, 98, 108-115.

81. Ojiambo, P.; Battilani, P.; Cary, J.; Blum, B.; Carbone, I. Cultural and Genetic Approaches to Manage Aflatoxin Contamination: Recent Insights Provide Opportunities for Improved Control. Phytopathology. 2018, 108, 1024-1037.

82. Elliott, C.; Connolly, L.; Kolawole, O. Potential adverse effects on animal health and performance caused by the addition of mineral adsorbents to feeds to reduce mycotoxin exposure. Mycotoxin Research. 2019, 36. 115-126.

83. Kolawole, O.; Meneely, J.; Greer, B.; Chevallier, O.; Jones, D.; Connolly, L.; Elliott, C. Comparative In Vitro Assessment of a Range of Commercial Feed Additives with Multiple Mycotoxin Binding Claims. Toxins. 2019, 11, 659.

84. Di Gregorio, M.C.; de Neeff, D.V.; Jager, A.V.; Corassin, C.H.; de Pinho Carão, A.C.; de Albuquerque, R.; de Azevedo, A.C.; Oliveira, C.A.F. Mineral adsorbent for prevention mycotoxins in animal feed. Toxin Reviews. 2014, 33, 125-135.

85. Soliman, K. M. Incidence, Level, and Behavior of Aflatoxins during Coffee Bean Roasting and Decaffeination. Journal of Agricultural and Food Chemistry. 2002, 50, 7477-7481. 10.1021/jf011338v

86. Zheng, H.; Wei, S.; Xu, Y.; Fan, M. Reduction of aflatoxin B1 in peanut meal by extrusion cooking. LWT - Food Science and Technology. 2015, 64, 515-519. https://doi.org/10.1016/j.1wt.2015.06.045

87. Pankaj, S. K.; Shi, H.; Keener, K. M. A review of novel physical and chemical decontamination technologies for aflatoxin in food. Trends in Food Science \& Technology. 2018, 71, 73-83. https://doi.org/10.1016/j.tifs.2017.11.007

88. Ghanghro, A. B.; Channa, M.J.; Sheikh, S.A.; Nizamani, S.M.; Ghanghro, I.H. Assessment of aflatoxin level in stored wheat of godowns of hyderabad division and decontamination by UV radiation. International Journal of Sciences. 2016, 8, 8-16.

http://dx.doi.org/10.12692/ijb/8.1.8-16 
89. Mohamed, N. F.; El-Dine, R.S.S.; Kotb, M.A.M.; Saber, A. Assessing the Possible Effect of Gamma Irradiation on the Reduction of aflatoxin B1, and on the Moisture Content in Some Cereal Grains. American Journal of Biomedical Sciences. 2015, 7, 33-39. doi:10.5099/aj150100033

90. Assunção, E.; Reis, T. A.; Baquião, A. C.; Corrêa, B. Effects of Gamma and Electron Beam Radiation on Brazil Nuts Artificially Inoculated with Aspergillus flavus. J Food Prot. 2015, 78, 1397-1401. https://doi.org/10.4315/0362-028x.Jfp-14-595

91. Misra, N. N.; Kadam, S.; and Pankaj, S. An overview of nonthermal technologies in food processing. Indian Food Industry. 2011, 30, 44-51

92. Savi, G. D.; Piacentini, K. C.; Scussel, V. M. Ozone Treatment Efficiency in Aspergillus and Penicillium Growth Inhibition and Mycotoxin Degradation of Stored Wheat Grains (Triticum aestivum L.). Journal of Food Processing and Preservation. 2015, 39, 940-948. doi:https://doi.org/10.1111/jfpp.12307

93. Porto, Y. D.; Trombete, F. M.; Freitas-Silva, O.; de Castro, I. M.; Direito, G. M.; Ascheri, J. L. Gaseous Ozonation to Reduce Aflatoxins Levels and Microbial Contamination in Corn Grits. Microorganisms. 2019, 7. https://doi.org/10.3390/microorganisms7080220

94. Chen, R.; Ma, F.; Li, P. W.; Zhang, W.; Ding, X. X.; Zhang, Q.; Li, M.; Wang, Y.R.; Xu, B. C. Effect of ozone on aflatoxins detoxification and nutritional quality of peanuts. Food Chem. 2013, 204, 146, 284-288. https://doi.org/10.1016/j.foodchem.2013.09.059

95. Jalali, L.; Avagyan, G. Evaluation of contamination of Aspergillus flavus and aflatoxin production in pistachio cultivars and investigation of a chemical controlling method. Journal of Nuts. 2014, 7, 51-58.

96. Ji, C.; Fan, Y.; Zhao, L. Review on biological degradation of mycotoxins. Animal nutrition. 2016, 2, 127-133. doi:10.1016/j.aninu.2016.07.003

97. Huynh, V. L.; Gerdes, R. G.; Lloyd, A. B. Synthesis and degradation of aflatoxins by Aspergillus parasiticus. II. Comparative toxicity and mutagenicity of aflatoxin B1 and its autolytic breakdown products. Aust J Biol Sci. 1984, 37, 123-129. doi:10.1071/bi9840123

98. Doyle, M. P.; Marth, E. H. Degradation of aflatoxin by lactoperoxidase. Z Lebensm Unters Forsch. 1978, 166, $271-273$. doi:10.1007/bf01127651

99. Wang, J.; Xie, Y. Review on microbial degradation of zearalenone and aflatoxins. Grain \& Oil Science and Technology. 2020, 3, 117-125. https://doi.org/10.1016/j.gaost.2020.05.002

100. Ma, Q. G.; Gao, X.; Zhou, T.; Zhao, L. H.; Fan, Y.; Li, X. Y.; Lei, Y.P.; Ji, C.; Zhang, J. Y. Protective effect of Bacillus subtilis ANSB060 on egg quality, biochemical and histopathological changes in layers exposed to aflatoxin B1. Poult Sci. 2012, 91, 2852-2857. doi:10.3382/ps.2012-02474

101. Fan, Y.; Zhao, L.; Ji, C.; Li, X.; Jia, R.; Xi, L.; Zhang, J.; Ma, Q. Protective Effects of Bacillus subtilis ANSB060 on Serum Biochemistry, Histopathological Changes and Antioxidant Enzyme Activities of Broilers Fed Moldy Peanut Meal Naturally Contaminated with Aflatoxins. Toxins. 2015, 7, 3330-3343. doi:10.3390/toxins7083330

102. Kong, Q.; Shan, S.; Liu, Q.; Wang, X.; Yu, F. Biocontrol of Aspergillus flavus on peanut kernels by use of a strain of marine Bacillus megaterium. International Journal of Food Microbiology. 2010, 139, 31-35. doi:https://doi.org/10.1016/j.ijfoodmicro.2010.01.036

103. Petchkongkaew, A.; Taillandier, P.; Gasaluck, P.; Lebrihi, A. Isolation of Bacillus spp. from Thai fermented soybean (Thua-nao): screening for aflatoxin B1 and ochratoxin A detoxification. J Appl Microbiol. 2008, 104, 1495-1502. doi:10.1111/j.1365-2672.2007.03700.x

104. Guan, L. Z.; Sun, Y. P.; Cai, J. S.; Wu, H. D.; Yu, L. Z.; Zhang, Y. L.; Xi, Q. Y. The aflatoxin-detoxifizyme specific expression in mouse parotid gland. Transgenic Res. 2015, 24, 489-496. doi:10.1007/s11248-015-9863-y

105. Das, A.; Bhattacharya, S.; Palaniswamy, M.; Angayarkanni, J. Biodegradation of aflatoxin B1 in contaminated rice straw by Pleurotus ostreatus MTCC 142 and Pleurotus ostreatus GHBBF10 in the presence of metal salts and surfactants. World J Microbiol Biotechnol. 2014, 30(8), 2315-2324. https://doi.org/10.1007/s11274-014-1657-5

106. Yehia, R. S. Aflatoxin detoxification by manganese peroxidase purified from Pleurotus ostreatus. Brazilian journal of microbiology. 2014, 45 , 127-133. doi:10.1590/S1517-83822014005000026 
107. Hackbart, H. C. S.; Machado, A. R.; Christ-Ribeiro, A.; Prietto, L.; Badiale-Furlong, E. Reduction of aflatoxins by Rhizopus oryzae and Trichoderma reesei. Mycotoxin Research. 2014, 30, 141-149. doi:10.1007/s12550-014-0202-6

108. Kim, S.; Lee, H.; Lee, S.; Lee, J.; Ha, J.; Choi, Y.; Yoon, Y.; and Choi, K.-H. Microbe-mediated aflatoxin decontamination of dairy products and feeds. Journal of Dairy Science. 2016, 100, 871-880. doi:https://doi.org/10.3168/jds.2016-11264 